\title{
Investigation of Termomodernized Building's Microclimate with Renewable Energy
}

\author{
Vitalii Nalyvaiko*, Ivan Radko, Andrii Zhyltsov, Oleksandr Okushko, \\ Anatolii Mishchenko, Ievgen Antypov \\ National University of Life and Environmental Sciences of Ukraine \\ 03041, Ukraine, Kyiv, Heroiv Oborony Str., 12,
}

\begin{abstract}
The values of indoor air temperatures in separate premises of the educational building of National University of Life and Environmental Sciences of Ukraine before and after the works on the thermomodernization of the building were determined. A significant reduction in energy expenditure was achieved through the use of solar panels and solar collectors when changing the energy control algorithm and equipment for implementing this algorithm. The coldest rooms and premises with excess temperature are detected.The causes of uneven distribution of temperatures were analyzed. The possibility of equalizing the distribution of internal air temperatures and reducing the dependence of their values on fluctuations of external air temperatures is shown. With the help of the engineering methodology of calculation, energy efficiency of the so-called intermittent heating mode is demonstrated on the example of an educational room.It is shown that the use of the intermittent heating method can reduce energy consumption for heating. To further reduce energy costs, it is proposed to use a heat pump to compensate for peak loads and work at night at a special rate.
\end{abstract}

\section{Introduction}

The beginning of a new direction of buildingsconstructionwith increased requirements for efficiency appeared after the global energy crisis on 1974. It was a respond on the criticism of the UN International Energy Conference (IEC) experts about the fact that modern buildings had significant reserves for increasing their thermal efficiency, but the researchers have not sufficiently studied the features of their thermal regime, and the designers were not able to optimize the flows of heat and mass in the external enclosures of the house in general. In the same report of the IEC specialists, the main idea of energy saving was formulated: energy resources can be used more effectively by applying measures that are technically feasible, economically justified, and acceptable from the environmental and social point of view, that is, causing minimal changes in the usual way of life. However, when implementing energy-saving measures, it is impossible to violate the premises comfort conditions, with the help of which the thermal balance in the human body is maintained and there is no tension in their system of thermoregulation. The first condition

\footnotetext{
* Corresponding author: nva041@ukr.net
} 
for the comfort of the temperature situation is the maintenance of such values of air temperature and external enclosure, so that the person in the center of the room, do not feel neither overheating, nor overcooling [1].

\section{The relevance of work}

The working day in educational buildings lasts 8 hours. It's an one third of a day. At this time it is necessary to maintain comfortable conditions - the temperature more than 18 ${ }^{\circ} \mathrm{C}$. During off-hours, thermal power can be reduced to a minimum, which would exclude the occurrence of accidents in thermal networks from overcooling at sub-zero external temperatures. Of course, the minimum thermal output during off-hours must be scientifically grounded, both technically and economically. Therefore, when forming a flow control algorithm, it is necessary to make a certain compromise decision taking into account all known factors. This is the main lever for reducing the cost of heat transfer. Of course, it is not easyto do, because the room is characterized by thermal inertia.

For most modern buildings (administrative buildings, schools, higher educational establishments, theaters, cinemas, a number of industrial premises, etc.), it is allowed to reduce the temperature of internal air below the normative value during the day, on weekends and holidays, in order to save energy consumption for their heating. Prior to the use of these premises for their intended purpose, the temperature regime must comply with the regulatory parameters. Such a mode of heating, when the temperature of the internal air is reduced for a period of time below the comfort value, is called «intermittent».

Tabunshchikov Yu.A. in his work [2]noted that intermittent heat supply, which is based on the reduction of the total amount of heat consumption, requires a higher supply of thermal energy during the "dispersal" period. It is shown that the intermittent heat supply is economically advantageous, usually at a relatively high temperature of the outside air, which takes place mainly during the transition periods of the year when the existing power of the building heating system can be used to "disperse" the premises.

The foregoing gives grounds for using the method of intermittent heating of the building as one of the ways to save energy on the heating of an educational building. However, it is important to find out the most optimal (in terms of energy saving) mode in which the reduction of air temperature in the classrooms can be carried out at night hours, holidays and during the vacation period with the reservation or forehanded restoration of the comfort conditions in the rooms before the beginning of the working hours.

The purpose of the research is looking for the ways to reduce energy consumption for heat supply of educational buildings based on the optimization of the heat transfer fluid delivery algorithm during the day.

\section{Materials and methods of research}

According to the educational building number 8 of NULES of Ukraine, built in 1965, energy audit resultsactual heating costs exceeded the normative ones over $10 \%$ [3]. The measurement of temperatures in separate premises of educational building number 8 in February-March, 2014 showed a non-compliance of temperatures with normalized values and a significant unevenness of distribution of temperatures in rooms [4]. During 2015, the insulation of external enclosing structures of the building was completed, with the increasing of their thermal resistance to the regulated GBNB.2.6-31: 2016 "Thermal insulation of buildings". In 2016 automated weather-dependent coolant parameters control system in the individual thermal unit was installed.

The measurement of temperatures in separate rooms of the building № 8 and the 
temperatures of the outside air was carried out by a miniature temperature data logger RC-1 with an internal temperature sensor. The data logger allows for the safe registration of temperature data, in which data can not be changed or erased.

Reader RC-1 was used to read the recorded data. The appearance of the measuring complex is shown in Fig. 1, and the main characteristics of the sensor is shown in Table 1 [4].

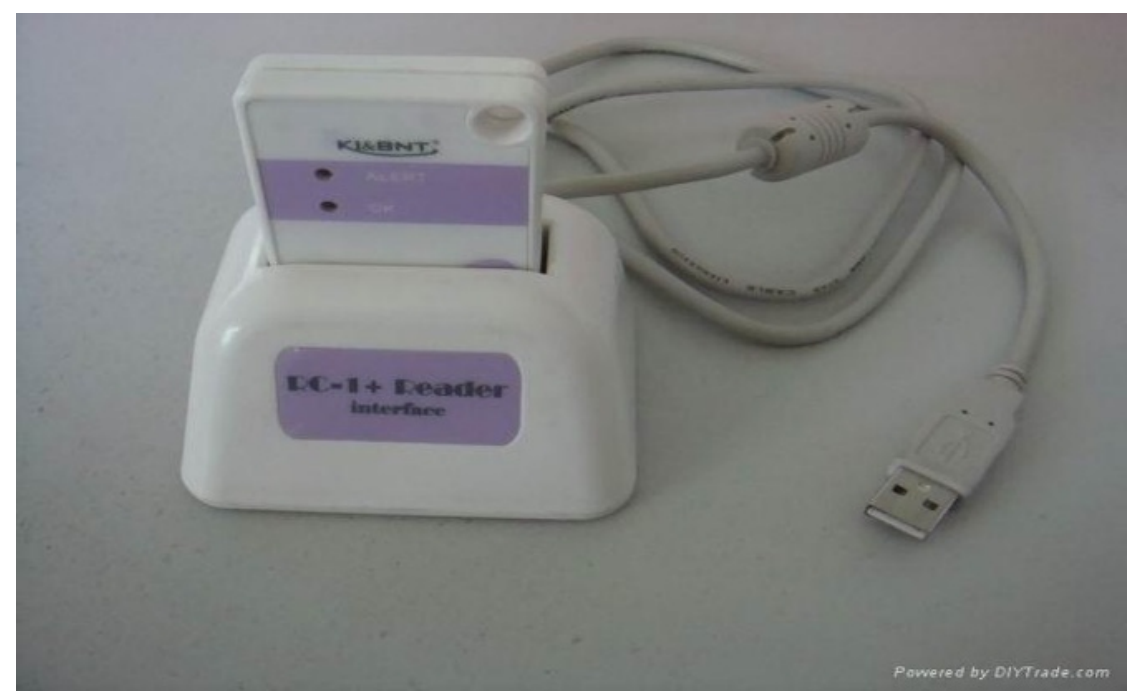

Fig. 1. The general appearance of the data logger RC-1

Table1. The characteristics of the RC-1data logger inner sensor [4].

\begin{tabular}{|c|c|c|}
\hline $\begin{array}{c}\text { Var } \\
\text { iant } \\
\text { № }\end{array}$ & Indicator & Value \\
\hline 1 & Working temperature & $-40^{\circ} \mathrm{C}-+70^{\circ} \mathrm{C}$ \\
\hline 2 & Measurement error & $1^{\circ} \mathrm{C}$ \\
\hline 3 & Limit differentiation & $0.1^{\circ} \mathrm{C}$ \\
\hline 4 & Record interval & 8000 spots \\
\hline 5 & Storage size & 89 days \\
\hline 6 & Maximum recording time & $\mathrm{USBinterface}$ \\
\hline 7 & Output & $45 \times 72 \times 13 \mathrm{~mm}$ \\
\hline 8 & Measurements & \\
\hline
\end{tabular}

To measure the thermal resistance of the fences of the building under stationary thermal mode, a heat transfer flux (PTP) type PTP was used - 1B.11.2.1.11.P.00.0. -GSTU 3756-98 [5]. It is made as an auxiliary wall, has a thermoelectric bimetallic multilayer sensitive element, which transforms the heat flow into an electric DC signal.

The range of measuring the heat flux density by such a device is $10-1000 \mathrm{~W} / \mathrm{m}^{2}$. The 
limits of permissible basic relative error is $\pm 4 \%$. The thermal resistance is up to $80{ }^{\circ} \mathrm{C}$. The coefficient of effective thermal conductivity is $0.8 \pm 0.05 \mathrm{~W} /(\mathrm{m} \cdot \mathrm{K})$. The conversion factor is $9.14 \mathrm{~W} /\left(\mathrm{m}^{2} \cdot \mathrm{mV}\right)$.

To measure the coolant parameters in the heat point, a heat meter - CA97 / 2M (with flowmeter section DN 15) was used. The class of accuracy of the device is 4 . The range of coolant consumption: the maximum is $2,39 \mathrm{~m}^{3} / \mathrm{h}$; the minimum is $1.32 \mathrm{~m}^{3} / \mathrm{h}$.

The temperature control of the coolant in the supply line with compensations for the temperature of the outside air was carried out by the heating controller and the hot water supply RVD 115/109.

The research was accompanied by a number of calculations. Equation for determining the thermal load of the heating system of the building $Q_{\text {heat }} \mathrm{kWt}$ is as follows:

$$
Q_{\text {heat }}=q_{0} \cdot \alpha \cdot V_{n} \cdot\left(t_{\text {ins }}^{b}-t_{\text {out }}\right),
$$

where: $q_{0}$ is specific heating characteristic of the building, $\mathrm{W} /\left(\mathrm{m}^{3} \cdot{ }^{\circ} \mathrm{C}\right) ; a$ is correction factor taking into account climatic conditions of the area; $V_{n}$ is external volume of the building, $\mathrm{m}^{3} ; t_{\text {ins }}{ }^{b}$ is average temperature of the building inside the room, ${ }^{\circ} \mathrm{C} ; t_{\text {out }}$ is estimated outside air temperature, ${ }^{\circ} \mathrm{C}$.

Based on the equation of the heatingof the building (1), an analysis of the effect of the operation of the heating devices on the microclimate of the room, that is, the temperature of the internal air was held. The estimated equation for the temperature of the internal air $t$, ${ }^{\circ} \mathrm{C}$, has the form:

On the basis of the equation of heatingof the building (1) an analysis of the influence of the operation mode of the heating devices on the microclimate of the room, that is, the temperature of the internal air was conducted. The estimated equation for the temperature of the internal air $\mathrm{t}_{\text {ins }},{ }^{\circ} \mathrm{C}$, looks like:

$$
t_{\text {ins }}=t_{\text {out }}+\frac{1}{q_{0} \cdot V_{n}} t_{\text {out }}\left[Q_{\mathrm{T} \theta} \frac{\left(\tau_{1}-t_{\text {out }}-\frac{Q_{\mathrm{T} B}}{q_{0} \cdot V_{H} \cdot \alpha}\right)}{\frac{1}{2 \cdot G \cdot c_{B}}+\frac{1}{k_{c o} \cdot F_{c o}}+\frac{1}{q_{0} \cdot V_{H} \cdot \alpha}}\right],
$$

where: $\tau_{1}$ is the temperature of direct network water, ${ }^{\circ} \mathrm{C} ; G$ is mass flow rate of direct network water entering from the heating network (or heat point) to the heating system of the building, $\mathrm{kg} / \mathrm{sec} ; k_{c o}$ is average heat transfer coefficient of the heating system, $\mathrm{Wt} /\left(\mathrm{M}^{2}\right.$. $\left.{ }^{\circ} \mathrm{C}\right) ; F_{c o}$ is total area of heat-transferring elements of the heating system, $\mathrm{M}^{2} ; Q_{\mathrm{T}}$ is the power of external heat dissipation (people, appliances, gas cookers, etc.), Wt; $c_{b}$ is specific heat capacity of water, $\mathrm{J} /\left(\mathrm{kg} \cdot{ }^{\circ} \mathrm{C}\right)$.

As a result of mathematical processing, an equation describing the dependence of the thermal energy consumption $\mathrm{Q}, \mathrm{Gcal} / \mathrm{h}$, on the temperature of the outside air is as follows:

$$
Q=-0,35 t_{p}+8,1 \text {. }
$$

With the help of simplified engineering method, the dynamics of the internal temperature change of the premises in the application of the intermittent heating method was calculated. The processes of cooling and heating of premises at a constant temperature of the outside air, when the supply of thermal energy is not equal to heat losses, were examined. The expected internal air temperature $t(\tau)$, whichwould appear indoors in an hourtafter the change in the thermal power of the heating devices, was determined by the formula by E.Y. Sokolov [6]:

$$
t_{B}(\tau)=t_{p}+\frac{Q_{0}}{q_{0} \cdot V}+\frac{t_{B}^{n}-t_{p}-\frac{Q_{0}}{\left(q_{0} \cdot V\right)}}{e^{\tau / \beta}}
$$


where $Q_{0}$ is an amount of heat supplied to the room from the heating system, Wt; $\tau$ is time, year; $\beta$ is the coefficient of thermal accumulation of premises, $1 /$ hour.

The results of calculations according to formulas $1-4$ are shown in Fig. 2 and Table 2.

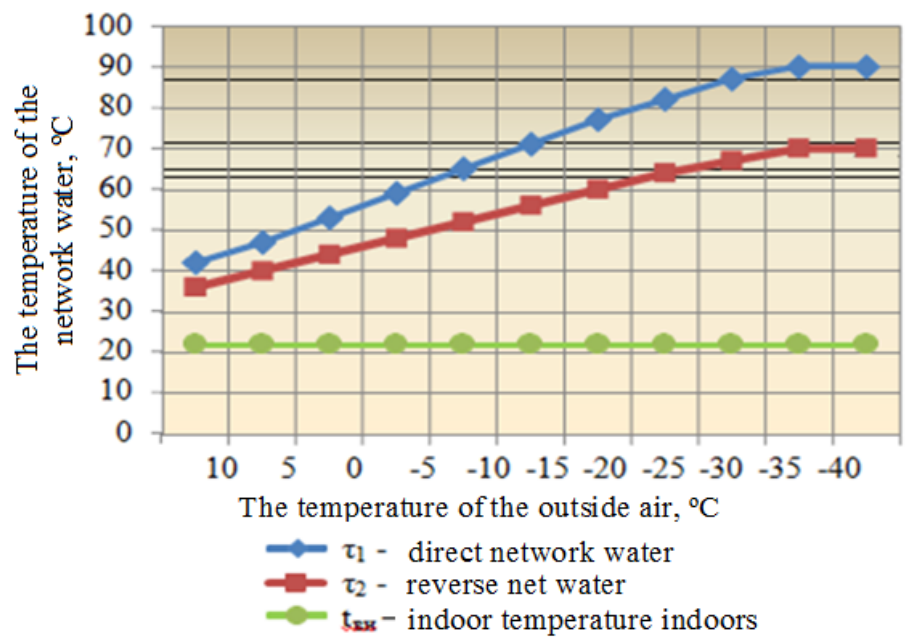

Fig. 2. The heating temperature schedule for heating system $90 / 70{ }^{\circ} \mathrm{C}$.

Table 2. The comparison of daily energy consumption for heating for different variants of controlling the thermal regime of premises [11].

\begin{tabular}{|c|c|c|c|c|}
\hline $\begin{array}{c}\text { Vari } \\
\text { ant } \\
\text { № }\end{array}$ & $\begin{array}{c}\text { The time off } \\
\text { of heating } \\
\text { devices, } \\
\text { hours }\end{array}$ & $\begin{array}{c}\text { The increase of the } \\
\text { capacity of heating } \\
\text { devices during the } \\
\text { heating of the } \\
\text { premises in } \\
\text { comparison with the } \\
\text { calculated one, } \%\end{array}$ & $\begin{array}{c}\text { Daily } \\
\text { energy } \\
\text { consumpti } \\
\text { on, kWt·h. }\end{array}$ & $\begin{array}{c}\text { The saving } \\
\text { of the heat } \\
\text { energy, \% } \\
\text { compared } \\
\text { to the } \\
\text { var.№1) }\end{array}$ \\
\hline 1 & 0 & 0 & 238,6 & 0 \\
\hline 2 & 8 & 30 & 191,8 & 19,6 \\
\hline 3 & 8 & 40 & 190,9 & 20,0 \\
\hline 4 & 8 & 50 & 193,8 & 18,8 \\
\hline
\end{tabular}

\section{The research results}

Before the thermo-modernization of the educational building, thepoints of the thermal resistance of the heat transfer of the outer walls was at the level of $0.7 \mathrm{~m}^{2} /(\mathrm{Wt} \mathrm{K})$, which is almost three times less than the normative $\left(\mathrm{R}=3.3 \mathrm{~m}^{2} /(\mathrm{Wt} \mathrm{K})\right)$. [7-9]. After application of a layer of external insulation (basalt-fiber slab thickness of $100 \mathrm{~mm}$ ) the points of thermal resistance were brought to normative.

During February and March 2018-2019, epymeasurements were made in two stages. The duration of each stage was determined in such a way that the frequency of the measurements was 7 temperature records per hour. 
At the first stage, a temperature control was carried out in room №4 (ground floor, south facade) and rooms №30 (third floor, north facade) and № 27 (third floor, southern facade). These measurements are shown in Fig. 3 [10].

As we can see,during the first decade of March, at low temperatures of the outside air, the temperature inside rooms №4 and №27 exceeded the normative at $2 . .3{ }^{\circ} \mathrm{C}$, and the temperature in room №30 was lower than in room №27 at about $3{ }^{\circ} \mathrm{C}$, that can not be explained only by the different orientation of these premises (south-north).

At the second stage, except rooms №4 and №30, the temperatures were measured in room №27, which is located on the third floor,the same as room №30, but is oriented towards the south, the same as room №4. The measurements were shown in Fig. 4 [10].

a)

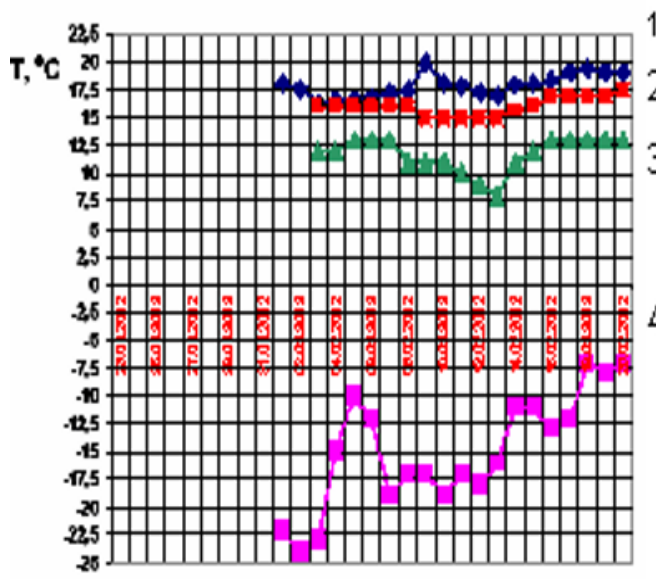

б)

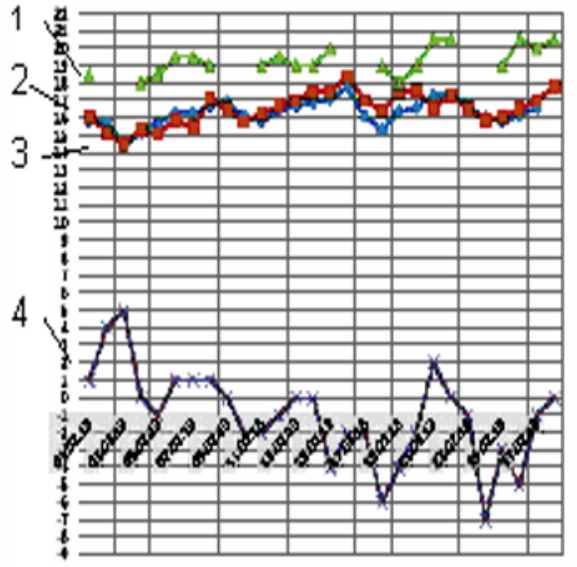

Fig. 3. The temperature change in separate rooms of building №8 in February 2014 (a) and in February 2018 (b) was: 1 - room №4; 2 - room №27; 3 - room № 30; 4 - the temperature of external air.

a)

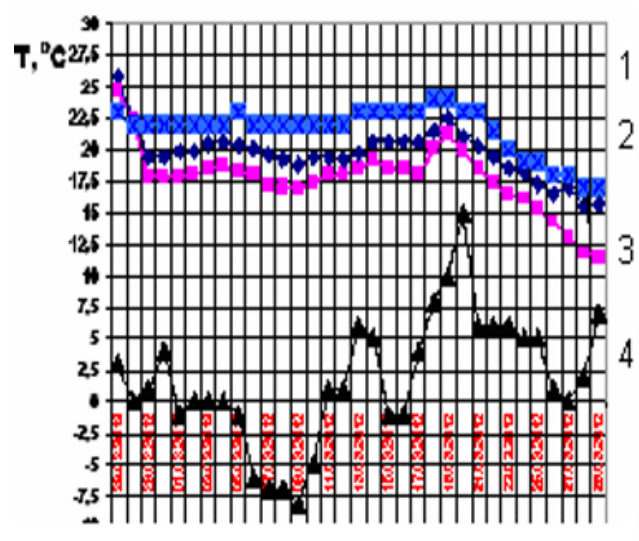

б)

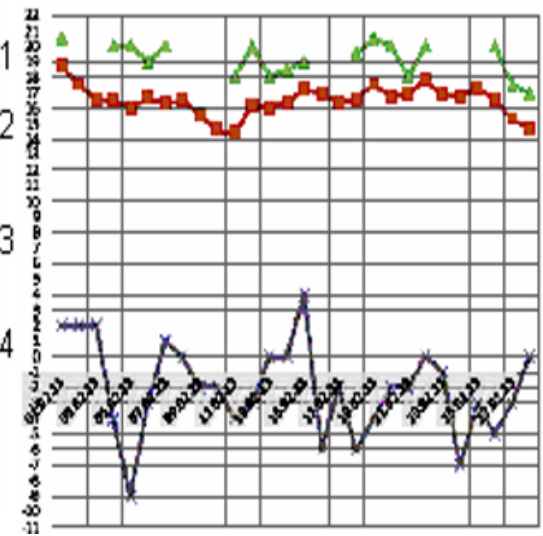

Fig. 4. Temperature change in separate rooms of building №8 in March 2014 (a) and in March 2018 (b): 1 - room №4; 2 - room №27; 3 - room №30; 4 - the temperature of external air.

As we can see, the temperatures in the rooms №4, №27, that are oriented to the south, practically remained at the level of 2014 , and the temperature in the room №30, oriented to the north, increased on average by $2 \ldots 4{ }^{\circ} \mathrm{C}$ and started meeting the norms for the premises 
of educational institutions.

According to the obtained data, the dependence of the air temperature from the surface in the premises of the building was determined (Fig. 5). According to the graphic, it can be seen that as the floor of the building increases, the temperature inside the premises decreases both on the northern and southern sides. This decrease is quite noticeable. So, on the south side the temperature drops by $4 \ldots 5$ degrees on the third floor in comparison with the first floor, and on the north this decrease is up to $3 \ldots 4$ degrees.

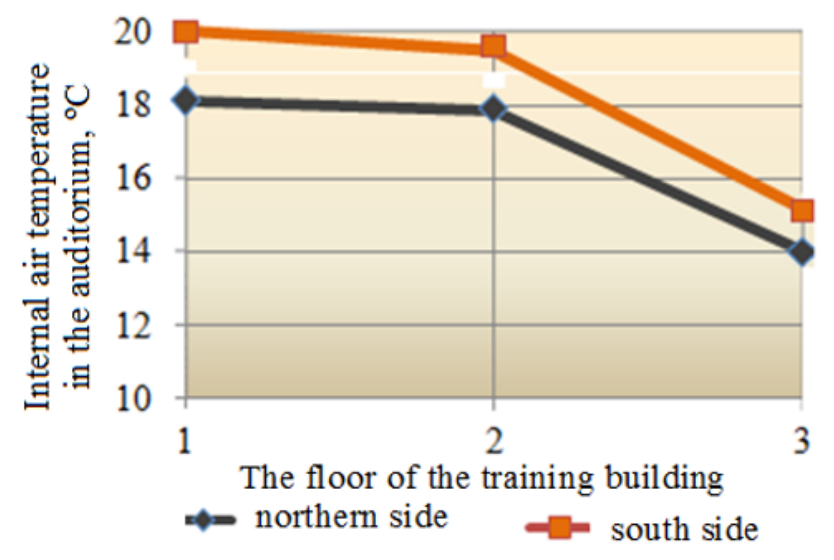

Fig. 5. The dependence of the temperature of air from the surface of the buildingin the premises.

So, for the uniform distribution of heat in premises with identical heating devices on all floors it is necessary to do calculations taking into account the temperature change on the floors to provide the necessary parameters of the microclimate.

Based on formulas (1) and (2), a heating temperature schedule for heat release regulation is developed (Figure 5). The temperature schedule has to be developed for each city, depending on local conditions. It clearly establishes what temperature of the network water in the heating network at a specific temperature of the outside airshould be.

The modernization of the heat point of the educational building №8 in 2016 with the installation of the system of automatic control of the parameters of the coolant, has allowed to reduce heat consumption for heating in the periods of increase of temperature of external air, as well as at night and on weekends (Fig. 6).

Also, the influence of heat supply conditions on the quality of heating before and after the installation of the ITP was considered. The calculation was made for cases where the heating of the premises was carried out with a capacity increase of 20, 30, 40 and $50 \%$. The time off of the heating devices was determined to be 8 hours. Table 2 shows the comparison of daily energy consumption to the heat supply of the room under different control modes of the thermal regime. In this case, the variant №1 corresponds to the case when the heating system was not regulated.

The table shows, that the most energy-saving regime is that in which the power of the heating device during the heating of the room is more than $40 \%$ compared to the calculated one for stationary mode. At the same time, according to calculations, the heating devices could be switched off at 16 o'clock, and switched on at 24 o'clock. After 8 hours of «dispersal", the temperature reaches $18{ }^{\circ} \mathrm{C}$ and the power of the heating devices decreases to the calculated one for comfortable stationary mode. 


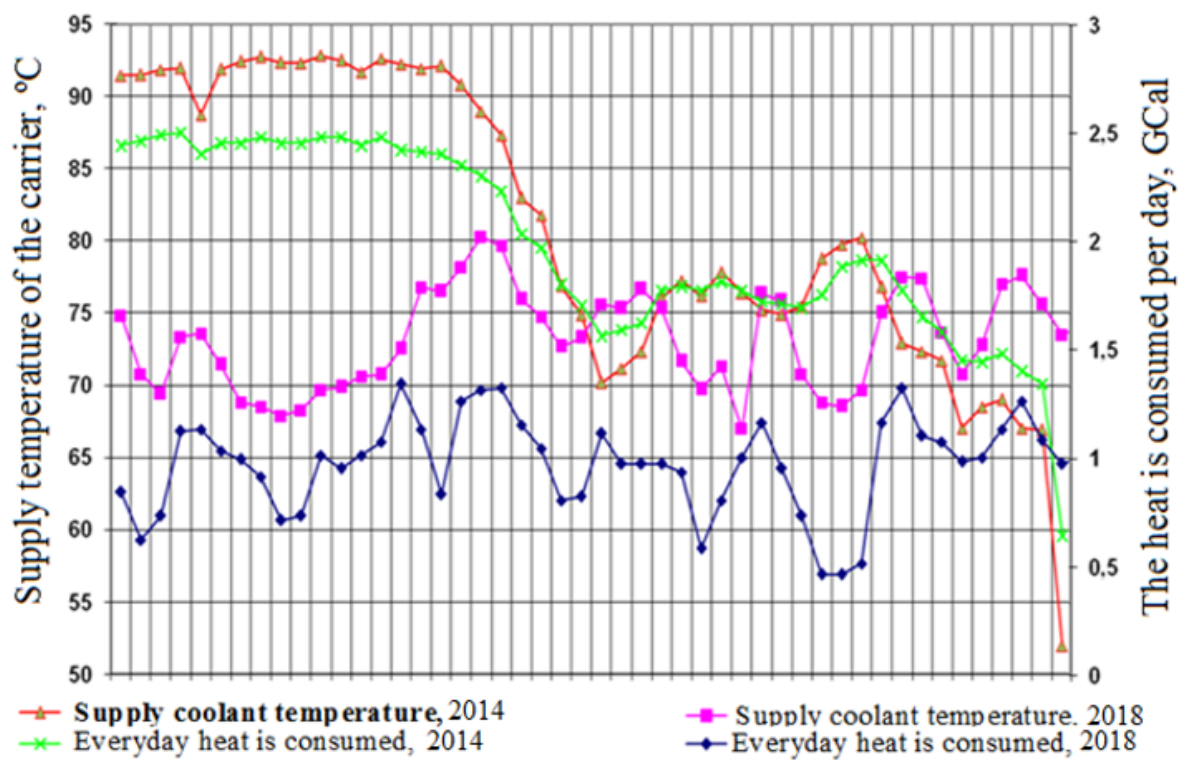

Fig. 6. Results of monitoring of the consumption of heat-carrier and thermal energy [10].

Thus, it has been shown that the use of the intermittent heating method reduces the energy consumption of heating. This method can be used to reduce the heating energy consumption in rooms where during the day it is necessary to maintain a comfortable temperature, and at night (as well as weekends, holidays etc.), it is also possible a shortterm reduction of temperature below a comfortable level.

The aforementioned technical measures allowed to reduce primary energy consumption by $60 \%$. But this was not enough to achieve the current level of energy efficient buildings. Therefore, in parallel with thermomodification work was carried out on the introduction of renewable energy sources. For the outdoor lighting of the building and the next lighting of the corridors, a local solar power system with $3.7 \mathrm{~kW}$ power batteries is installed. This power is quite enough when using LED lamps.

To reduce electricity consumption on the roof of the building, solar panels with a total installed capacity of $31 \mathrm{~kW}$ were installed, which produced $38920 \mathrm{kWh}$ of electricity during 2018 (Fig. 7). This power is not enough to cover all the peak needs of the training building. But, since the solar panels work in parallel with the central network, the total annual energy balance is close to zero. Installed equipment with renewable energy sources is used both for technical needs and for conducting scientific researches in the course of execution by students of master's works.

The heating of water for technological needs is carried out at the expense of 4 solar collectors, which on solar day can heat up to $1 \mathrm{~m}^{3}$ of water to a temperature of $50{ }^{\circ} \mathrm{C}$. 


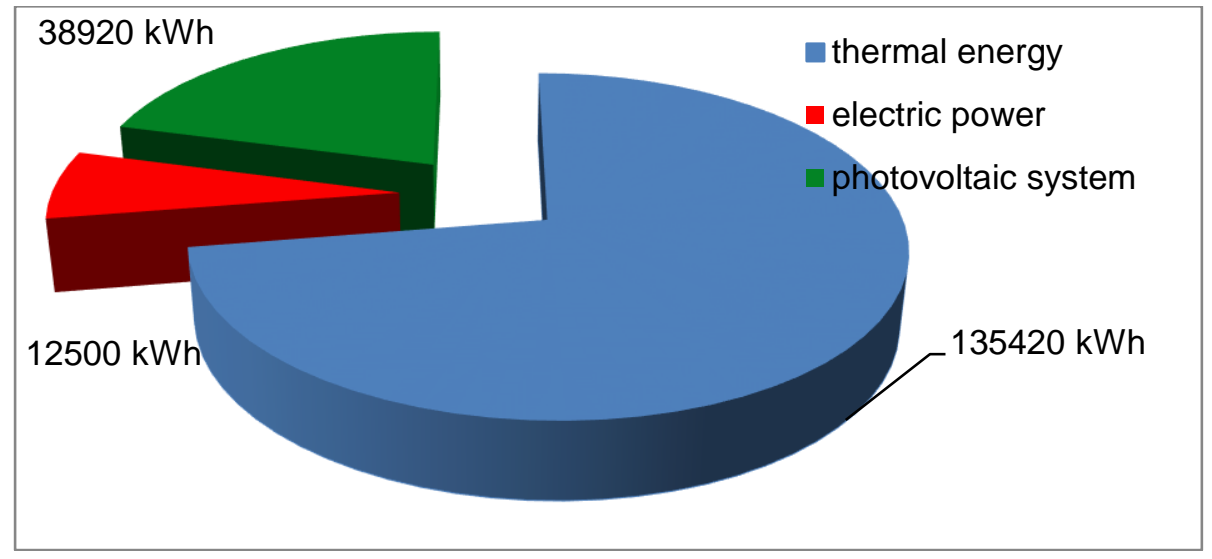

a)

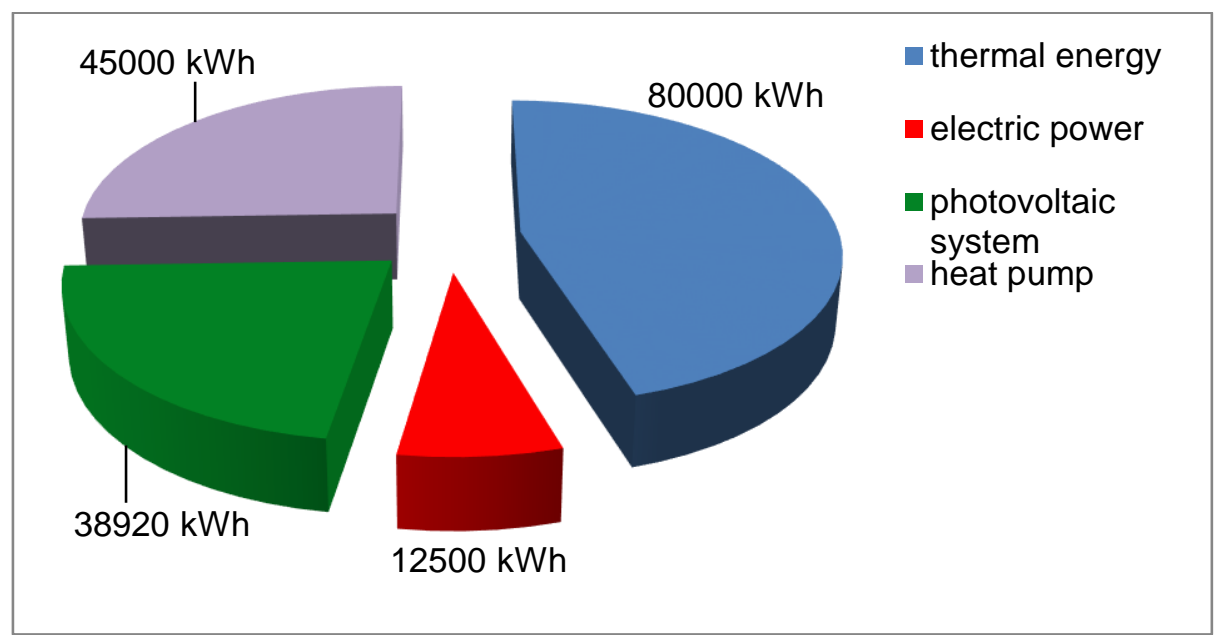

b)

Fig. 7. Energy balance: a) 2018 year, б) prognosis 2020 year.

To date, the training building for 2018 has used a total of $31 \mathrm{kWh} / \mathrm{m} 3$, which is 3.4 times less than in 2012. This allows us to attribute this building to class C. A significant decrease in total energy costs can be explained not only by the introduction of technical measures but also by organizational measures. The sharp rise in energy tariffs forced the work of service providers to be adjusted, amendments were made to the schedule of work and training of students, and to create additional motivations for the organization of the work of each university employee.

The resource for energy efficiency is not exhausted at all. In the next 2 years it is planned to reach the energy efficiency class B (Figure 7) due to:

1. Installing additional transparent energy-saving screens on the windows, which will reduce about $50 \%$ of the heat loss through the windows and reduce the total cost of heat energy by $12 \%$.

2. The return of the heat of ventilation air when installing heat exchangers with intelligent control will reduce total energy costs by $7 \%$.

3. Installation of a heat pump with thermal power of $50 \mathrm{~kW}$ to cover peak loads at the moment of system overclocking and work at night. (The use of such a source when working 
from 23:00 to 7:00 at a night rate in monetary terms is equivalent to a consumer with a power of $5 \mathrm{~kW}$ ).

\section{Conclusions}

As a result of the research, the following wasdetermined.

1. Increasing the energy efficiency of existing buildings to a modern level is possible through an integrated approach that includes thermal modification of the building, replacement of equipment and energy supply management algorithm, and the use of renewable sources in general and local electrical networks.

2. The dependence of the thermal energy consumption on the temperature of the outside air for a specific building is determined. As a result of mathematical processing, an equation describing this dependence is obtained.

3. Applying the above-mentioned dependence to the algorithm for control of the thermal point with the help of intermittent method, up to $20 \%$ of thermal energy could be saved. The power of the heat point for heating the room to a comfortable internal temperature should be higher than its calculated value for stationary mode. To cover peak thermal loads and work at night at a special rate it is expedient to use a heat pump.

4. The dependence of the air temperature in the room from the surface of the building is found. It was shown that the difference between the temperatures on floors 1 and 3 reached $5{ }^{\circ} \mathrm{C}$. Therefore, for the uniform heating of premises on all floors, the heating system should be supplemented with local heat carrier supply regulators.

5.The thermo-modernization of the building reduces significantlythe dependence of the temperature in the room from fluctuations in the temperature of the outside air.

\section{References}

1. K.R. Safiulina, A.G. Kolinko, R.Yu. Tormasov, Energy saving in campuses, 328 (2010)

2. Yu.A. Tabunshchikov, M.M. Brodach, Mathematical modeling and optimization of thermal efficiency of buildings, 204 (2012)

3. V.V. Kozyrsky, O. M. Bereka, O.V. Shelimanova, Ye.O. Antipov, Power Engineering and automatics, 1 (12), 55 - 63 (2012)

4. A.V. Mishchenko, O.V. Shelimanova, O.E. Olenev, Scientific writer of NULES of Ukraine, 174, 63 - 66 (2012)

5. O.A. Gerashchenko, A.N. Gordov, V.I. Lakh and other, Temperature measurements: book of references, 493 (1984)

6. E. Ya. Sokolov, Thermalification and thermal networks, 472 (2001)

7. Thermal insulation of buildings: DBN V.2.6-31: 2016. Kiyv: Ministry of Construction, Architecture and Housing and Communal Services of Ukraine, 31 (2017)

8. I.P. Radko, V.A. Nalyvayko, O.V. Okushko, A.V. Mishchenko, Ye.O. Antypov, Power Engineering and Automatics, 1, 123 - 134 (2018)

9. I.P. Radko, V.A. Nalyvayko, O.V. Okushko, A.V. Mischenko, Ye.O. Antipov, Scientific herald of the National University of Life and Environmental Sciences of Ukraine, 283, $275-280$ (2018)

10. A.V. Mishchenko, O.V. Shelimanova, Ye.O. Antipov, Scientific herald of the National University of Life and Environmental Sciences of Ukraine, 194 (1), 119 - 123 (2014)

11. O.O. Kuznetsova, Visnyk of the KNUTD, 5 (79), $44-47$ (2014) 